\title{
Cartografia da Publicação Brasileira em Saúde Mental: 1980 - 1996
}

\author{
Izabel Christina Friche Passos ${ }^{2}$ \\ Universidade Federal de Minas Gerais
}

\begin{abstract}
RESUMO - O objetivo do presente estudo é mapear a ocorrência, importância e evolução da investigação científica pertinente ao processo de reforma psiquiátrica em curso no Brasil nas duas últimas décadas. A partir de levantamento por amostragem, feito no banco de dados LILACS - Literatura Latino-Americana en Ciencias de la Salud, traçam-se tendências e características das publicações desse período em que ocorreram acentuadas mudanças nas práticas e nos discursos que povoam o campo da saúde mental no país.
\end{abstract}

Palavras-chave: produção científica; periódicos; saúde mental; reforma psiquiátrica; desinstitucionalização.

\section{Charting Brazilian Publications in Mental Health: 1980 - 1996}

\begin{abstract}
The purpose of this paper is to indicate the occurrence, importance and evolution of the scientific investigation related to the process of the psychiatric reform, which has been taking place in Brazil for the last two decades. Based on the sample from data found at LILACS (Latin-American Literature on Health Science), on traced the trends and characteristics of the published material from the periodon in which deep changes related to the practice and the discourse that permeate the field of mental health in Brazil occured.
\end{abstract}

Key words: scientific production; journals; mental health; psychiatric reform; deinstitutionalization.

O objetivo deste trabalho é esboçar uma cartografia da produção científica brasileira no campo da saúde mental nas duas últimas décadas - período em que toma corpo um novo movimento de reforma psiquiátrica no Brasil. Trata-se de um mapeamento da ocorrência, importância e evolução da investigação científica em um novo campo de práticas e discursos. Na verdade, apresenta-se apenas um esboço do perfil da produção científica nacional em questão a partir de uma amostragem que cobre o período de 1980 a 1996. Não se tem a pretensão de alcançar o sentido amplo que Paulo Amarante (1995) propõe para cartografia, como “...produção de um olhar sobre fatos, cenários e atores" (p.48) em certo contexto de práticas, neste caso, em franca transformação.

Inicialmente, nossa intenção era de analisar apenas pesquisas qualitativas, isto é, aquelas relacionadas à análise, discussão ou avaliação de serviços modificados de saúde mental, ligadas ao contexto da reforma e afinadas com uma perspectiva qualitativa. Tínhamos, então, um objetivo mais restrito, embora talvez mais complexo, de fazer uma análise do conteúdo metodológico desses trabalhos, com o fim de delimitar alcances e limites da estratégia qualitativa em investigações no campo da reforma. O alargamento dos objetivos para a realização de uma cartografia da produção científica em saúde mental, a partir de uma análise da amostra, possibilitou tanto incluir pesquisas quantitativas e outros tipos de publicação, quanto construir um panorama informativo mais geral sobre essa produção. Fica ressalvado,

1 Pesquisa realizada com apoio da CAPES, durante o doutoramento da autora, sob a orientação de Pedro Gabriel Delgado. Agradecimentos aos funcionários da biblioteca da Escola Nacional de Saúde Pública da FIOCRUZ/RJ e a Paulo Amarante (Laboratório de Estudos e Pesquisas em Saúde Mental -FIOCRUZ).

2 Endereço: Universidade Federal de Minas Gerais FAFICH/Departamento de Psicologia. Av. Antônio Carlos, 6627. 31270-901 Belo Horizonte, MG, Brasil. E-mail: izabelpassos@ fafich.ufmg.br entretanto, o caráter parcial do levantamento que incita novas complementações ${ }^{3}$.

Tal cartografia resultou da análise de publicações nacionais no campo da saúde mental, especificamente no que se refere à relação que estabelecem com o processo de Reforma Psiquiátrica em curso. Por Reforma Psiquiátrica, entendese desde o conjunto de medidas oficiais (políticas, planos e alterações na lei visando à desospitalização e à reforma da assistência psiquiátrica) até o movimento social mais amplo, envolvendo trabalhadores da saúde mental, usuários, familiares e entidades da sociedade civil, numa luta pela transformação da condição de cidadania dos doentes mentais. Este movimento pode ser compreendido enquanto revisão crítica (teórica, ética, política e jurídica) das práticas e discursos sobre a doença mental e os chamados doentes mentais. Implica em tentativas de mudanças mais profundas, não só nos aspectos da lei, das políticas públicas e das práticas de cuidados, mas, igualmente, nos valores e significações sociais em torno da loucura e da doença mental.

À diferença de outros processos históricos reformistas, ocorridos anteriormente no Brasil, este tem se caracterizado, explicitamente, como um campo de luta entre o modelo tradicional hospitalocêntrico, centrado na hospitalização e no poder/saber psiquiátricos, e propostas críticas a esse modelo. Não se trata, portanto, de um processo hegemônico. Muito ao contrário, é um processo de quebra da hegemonia de poder, o que tem implicado no enfrentamento de muitas contradições.

Considerado em seu sentido amplo, o campo da reforma psiquiátrica tampouco é homogêneo. Como aponta Jane Russo (1996), há divisões internas, que os autores denominam “divisões de trabalho". De um lado, uma divisão entre

3 Estudo sobre as publicações posteriores ao período demarcado está sendo objeto de novo projeto de pesquisa. 
"reformadores e tecnocratas da psiquiatria e aqueles que defendem a reforma psiquiátrica em sua amplitude" ( p.96). Por parte dos primeiros, numa preocupação clara de preservação do saber psiquiátrico, "assiste-se a um grande avanço da psicofarmacologia, da chamada 'psiquiatria biológica'” (p.96). A outra divisão de trabalho, seria "interna aos próprios militantes da reforma psiquiátrica: os que se preocupam com a questão política (dos direitos dos doentes mentais à cidadania plena ... direito à diferença e à sua dignidade) versus aqueles que vêem como fundamental a questão técnica propriamente dita... (o manejo clínico da psicose)" ( p.97).

A autora reconhece o esquematismo de sua colocação, mas, de todo modo, pensa ser "correspondente a algumas representações correntes no meio" (p.97). De acordo com Russo, esta segunda divisão, além de frágil, já que nesta questão o político e o técnico se imbricam, não suprime aquilo que unifica o movimento: o esforço comum de transformação do significado social da doença mental. O processo atual tem posto em discussão a própria noção de desinstitucionalização. Uma discussão sobre esta noção, bem como a transformação histórica de seu sentido, exigiria longa consideração dos diversos processos de reforma psiquiátrica ocorridos nos países ocidentais, de modo a se fazer uma correta diferenciação entre modelos. Estes vão da mera desospitalização (modelo norte-americano) a propostas radicais de desconstrução do aparato e do saber psiquiátricos (modelo italiano). Para uma compreensão da distinção do termo nestes dois modelos, e da dimensão irredutível à idéia de desospitalização proposta pelos italianos, é fundamental o trabalho organizado por Fernanda Nicácio (1990). Para o esclarecimento deste debate entre nós, destacam-se o texto de Joel Birman (1992) e os trabalhos de Amarante $(1995,1996)$.

A partir desta sucinta delimitação das forças que compõem o campo da reforma, irá nos interessar, nesta cartografia, a identificação de aspectos marcantes, tendências temáticas e perspectivas metodológicas que têm caracterizado a produção científica no campo. Especialmente a que trata das recentes mudanças institucionais, organizadoras e teóricas de dispositivos de atenção à saúde mental. Em outras palavras, pretende-se identificar ocorrências e tendências marcantes de um período onde se intensifica o debate sobre formas de tratamento e cuidados aos doentes mentais. Estamos considerando que a partir de 1980, o movimento de Reforma Psiquiátrica já existe como tal, tendo sido convencionado o ano de 1979 como seu marco inicial. De fato, importantes acontecimentos marcam a passagem das décadas de 70 e 80 , dentre outros, a criação do Movimento dos Trabalhadores de Saúde Mental (MTSM), em 1978, que realizou seu primeiro Congresso em janeiro de 1979; a instauração pelo Congresso Nacional, em 1980, de uma CPI (Comissão Parlamentar de Inquérito) visando apurar irregularidades na assistência psiquiátrica, originada por várias denúncias das condições subumanas dos manicômios brasileiros; a realização do II Encontro Nacional do MTSM, em agosto de 1980.

\section{Algumas Considerações Metodológicas}

As análises da produção científica do campo da reforma, apresentadas neste texto a partir de um estudo por amostragem, devem ser consideradas como indicativas de tendências.
Como tal, não pretendem ser exaustivas. Algumas limitações do levantamento devem ser consideradas.

Por um lado, o trabalho contempla informações extraídas apenas do banco de dados LILACS-Literatura Latino-americana en Ciencias de La Salud, o qual abrange publicações em periódicos, documentos oficiais, alguns livros e teses acadêmicas. Uma consulta à fonte ANTARES do IBICT (Instituto Brasileiro de Informação em Ciência e Tecnologia), que reúne dissertações e teses existentes em bibliotecas universitárias brasileiras, poderia enriquecer a amostra e, portanto, as análises. No entanto, dificuldades de ordem técnica inviabilizaram na época tal consulta ${ }^{4}$. Por outro lado, é necessário reconhecer que todo banco de dados, por mais representativo que seja, como é o caso da LILACS, possui contingências de indexação, o que pode determinar bias na pesquisa. O objetivo principal dessa fonte são artigos de periódicos.

A análise quantitativa foi circunscrita aos dados da fonte, enquanto que a análise qualitativa foi complementada por consultas a livros e importantes periódicos específicos da área da saúde mental da cidade do Rio de Janeiro, local onde foi feito o levantamento. São eles: a Revista Physis, os Cadernos do IMS (ambos do Instituto de Medicina Social da Universidade Estadual do Rio de Janeiro), e os Cadernos IPUB (do Instituto de Psiquiatria da Universidade Federal do Rio de Janeiro).

É importante ter-se em conta que as considerações e conclusões aqui apresentadas são contingentes ao universo pesquisado (cuja indexação no banco vai até o ano de 1996, parcialmente). Outro aspecto que limita o alcance do levantamento é a não inclusão de trabalhos não publicados ou apenas mimeografados para circulação local e restrita. Pedro Gabriel Delgado, em comunicação pessoal, alertou para uma particularidade do campo. Caracterizado por um movimento social de amplo espectro, o campo conta com grande produção nacional em termos de experiências, projetos e reflexões teóricas não publicados formalmente. É forçoso considerar esta produção tão importante quanto os trabalhos publicados. Fica registrado, para consultas futuras, o esforço de organização desse tipo de material, que vem sendo empreendido pelo Laboratório de Estudos e Pesquisas em Saúde Mental do Núcleo de Estudos Políticos-Sociais em Saúde (NUPES), da Escola Nacional de Saúde Pública da Fundação Oswaldo Cruz - FIOCRUZ, sob a coordenação de Paulo Amarante.

\section{Delimitação da amostra}

A amostra foi obtida selecionando-se na LILACS, exclusivamente, trabalhos publicados no Brasil nas décadas de 80 e 90, no período que vai de 1980 a 1996 (parcialmente), sob os seguintes descritores, após consulta ao índice geral: "saúde mental", "serviços de saúde mental", "serviços comunitários

4 O professor Éder Leone (2000), da UNISUL, realizou trabalho semelhante especificamente sobre a produção acadêmica brasileira em saúde mental (dissertações e teses) correspondente ao período que de 1990 a 1997 . O autor realizou uma interessante análise epistemológica, classificando os trabalhos em duas vertentes, uma psiquiatrizante e outra despsiquiatrizante, tomando por referência três modelos internacionais de reforma. 
de saúde mental", "centros comunitários de saúde mental", "reforma" e "desinstitucionalização".

Vários outros descritores não foram incluídos, como por exemplo, aqueles relacionados à "psiquiatria”. Além de existirem 27 descritores diferentes para este assunto (por exemplo: serviços de emergência psiquiátrica, psiquiatria jurídica, psiquiatria preventiva...), o mesmo pareceu muito geral, o que dificultaria o trabalho de análise, dada a extensão do material. Uma análise rápida destes descritores demonstrou, ademais, que a amostra selecionada era bastante representativa das publicações relacionadas ao objetivo deste trabalho e, em grande maioria, apareciam nos descritores excluídos, inclusive no caso do descritor "hospitais psiquiátricos". Este continha algumas poucas referências importantes, não presentes na amostra. Outro descritor não consultado foi "loucura", por se tratar de assunto vastíssimo e inespecífico.

A amostra inicial incluiu 448 referências. Em números brutos, este total correspondia a aproximadamente $40 \%$ de todas as referências indexadas pela LILACS, sob os descritores selecionados. Como se sabe, este banco de dados indexa publicações do campo da saúde de toda a América Latina, o que torna bastante significativa a participação brasileira, pelo menos em termos quantitativos.

Destas 448 referências, 75 eram repetições, em subtítulos, de publicações já mencionadas (coletâneas de textos reunidos em livros, anais ou relatórios). Como apenas algumas coletâneas indexadas estavam detalhadas em seus artigos, para efeito de nivelamento do número total de referências, consideramos apenas o título da coletânea, caindo, assim, para 373 o número total de referências consideradas na análise quantitativa.

Dentre as 373 referências obtidas, merece destaque o fato de seis referências corresponderem a experiências realizadas em outros países (Cuba, Guiné Bissau e Chile) e a reflexões teóricas de autores estrangeiros. Como todas estavam publicadas em periódicos brasileiros, e relacionadas às atuais transformações da saúde mental, foram consideradas pertinentes à amostra.

A análise foi feita a partir, unicamente, da leitura dos resumos dos trabalhos e demais dados bibliográficos constantes na fonte. Só em pouquíssimos casos, constatou-se ausência de resumos. Vale ressaltar que alguns resumos são bastante detalhados.

\section{Resultados e Discussão}

As 373 referências da amostra eram oriundas das mais diversas fontes. Incluíam: a) aproximadamente 241 artigos de 49 revistas; b) 37 livros; c) 39 trabalhos acadêmicos (32 dissertações de mestrado, seis teses de doutorado e uma de livre docência); d) 39 publicações de órgãos oficiais definidores de políticas de saúde mental (federais, estaduais e municipais, e duas da Organização Panamericana da Saúde - OPAS); e) 17 publicações de eventos, organizados pelo movimento (MTSM) ou por entidades de classe. Nesses números, chama a atenção a baixa quantidade de teses de doutorado em relação a dissertações de mestrado. Em 1997, um grande jornal da cidade do Rio de Janeiro, publicava dados de um levantamento sobre pós-graduação, segundo o qual, para cada 100 doutores nos EUA, existia um no Brasil.
Tal situação vem sofrendo modificação acelerada nos últimos anos, com o aumento do número de doutores no país, reflexo da multiplicação de cursos de pós-graduação.

Outro aspecto que sobressai na composição da amostra é o representativo número de publicações oficiais (relatórios, manuais, orientações políticas e textos autorais veiculados por órgãos oficiais de saúde do governo, nos níveis federal, estadual e municipal). Esse dado, seguramente, está relacionado à análise da trajetória do movimento de reforma psiquiátrica feita por Amarante (1995), segundo a qual ocorre, num primeiro momento, uma importante "incorporação dos quadros do MTSM (Movimento dos Trabalhadores de Saúde Mental) no aparelho público, formulando e gerenciando as políticas públicas de saúde mental e a assistência psiquiátrica" (p.76-77). Além disso, ou ainda reflexo disso, é que a maioria dos relatórios oficiais de avaliação de serviços e de mudanças nas políticas públicas está circunscrita ao eixo Brasília-Rio-São Paulo. De outro lado, o número de publicações de eventos do movimento, propriamente dito, é bem menor. Excetuando os congressos nacionais e alguns encontros regionais do MTSM, fica de fora a maioria das publicações de encontros, seminários, simpósios realizados em todo o país por esse movimento e pelo movimento de Luta Antimanicomial, que emerge de uma radicalização do processo, durante o segundo congresso nacional do MTSM, realizado em Bauru/SP, em 1987.

Em relação aos periódicos, com a única exceção da Revista de Administração Pública, todas as 48 revistas são diretamente relacionadas à medicina, saúde pública ou áreas afins à saúde, sendo 10 delas de psiquiatria e saúde mental. Dentre as revistas mais diretamente relacionadas ao tema 'saúde mental', as que aparecem com mais trabalhos indexados estão relacionadas, em ordem decrescente, na tabela 1

Dentre as revistas de saúde pública, as que apresentam mais trabalhos pertinentes a este estudo estão relacionadas na tabela 2.

Os 82 artigos restantes (34\% da amostra), não computados nas tabelas 1 e 2 , encontram-se distribuídos pelos demais 37 periódicos da amostra.

Dada a antigüidade, a constância na periodicidade de publicação e o grande prestígio nacional do Jornal Brasileiro de Psiquiatria (JBP), não foi surpresa constatarmos que se trata do periódico com maior número de artigos indexados. No entanto, não se pode considerá-lo como particularmente

Tabela 1. Periódicos relacionados à área da saúde mental com mais de cinco artigos na amostra

\begin{tabular}{lcc}
\hline \multicolumn{1}{c}{ Periódico } & $\begin{array}{c}\text { Número } \\
\text { de Artigos }\end{array}$ & $\begin{array}{c}\text { Percentagem } \\
\text { na Amostra } \\
\text { N=241 }\end{array}$ \\
\hline Jornal Brasileiro de Psiquiatria/UFRJ & 58 & $24,1 \%$ \\
Revista da ABP - APAL & 15 & $6,2 \%$ \\
Psicologia: Teoria e Pesquisa & 12 & $5,0 \%$ \\
Revista de Terapia Ocupacional & 11 & $4,6 \%$ \\
Neurobiologia & 11 & $4,6 \%$ \\
Revista de Medicina de Ribeirão & 09 & $3,7 \%$ \\
Preto/USP & & \\
Boletim de Psiquiatria & 07 & $2,9 \%$ \\
Revista de Psiquiatria do RS & 06 & $2,5 \%$ \\
\hline Total & 129 & $53,6 \%$ \\
\hline
\end{tabular}


Tabela 2. Periódicos em saúde pública com mais trabalhos pertinentes ao estudo

\begin{tabular}{lcc}
\hline \multicolumn{1}{c}{ Periódico } & $\begin{array}{c}\text { Número } \\
\text { de Artigos }\end{array}$ & $\begin{array}{c}\text { Percentagem } \\
\text { na Amostra } \\
\text { N = 241 }\end{array}$ \\
\hline Revista de Saúde Pública da USP & 10 & $4,1 \%$ \\
Saúde em Debate do CEBES & 09 & $3,7 \%$ \\
Saúde Brasileira & 06 & $2,5 \%$ \\
Cadernos de Saúde Pública/FIOCRUZ & 05 & $2,1 \%$ \\
\hline Total & 30 & $12,4 \%$ \\
\hline
\end{tabular}

identificado com a divulgação do movimento de desinstitucionalização, em sua vertente mais radical. Seria surpreendente que um veículo de divulgação científica de traço fortemente "profissionalista" e especialista fosse cumprir tal papel. Por um lado, é preciso considerar que a história desse periódico contribuiu para a própria consolidação da psiquiatria como especialidade médica no Brasil. Por outro, uma das características fundamentais de parcela significativa do atual Movimento Antimanicomial, que compõe o campo da reforma, vem a ser precisamente a crítica radical ao saber psiquiátrico constituído e tradicional. Apesar do perfil histórico do periódico, analisando algumas transformações na composição do corpo editorial do JBP nos últimos anos, podemos constatar a incorporação de importantes teóricos críticos à instituição psiquiátrica, o que nos leva a concluir que o periódico continua sendo um dos principais espaços formais de publicação, também para trabalhos com perspectiva mais crítica e representativos do movimento de base da reforma.

É digno de registro o fato de apenas uma revista trazer referência explícita em seu título à saúde mental, é o Arquivo da Coordenação de Saúde Mental do Estado de São Paulo. A série paulista Saúde Loucura, da coleção Saúde em Debate da ABRASCO/HUCITEC, que reúne trabalhos identificados com as tendências mais avançadas do campo, não foi incluída entre as 49 revistas, mas classificada como livro, dado seu formato de impressão e a não regularidade na publicação.

A noção de saúde mental foi, ela própria, submetida a pormenorizada e dura análise crítica por Joel Birman e Jurandir Freire Costa (1994), em texto intitulado "Organização de instituições para uma psiquiatria comunitária" e datado de 1976, portanto, bem anterior à constituição do movimento de reforma. Esse texto permaneceu praticamente desconhecido, pois publicado apenas em anais de um congresso de psiquiatria da época, até que Amarante o reeditou em livro, em 1994. Muitas das críticas permanecem atuais e procedentes.

É importante sublinhar que duas revistas especializadas em disciplinas científicas não-médicas, a saber, Psicologia: Teoria e Pesquisa (com 5\% de artigos da amostra) e Revista de Terapia Ocupacional (com 4,6\%), vêm em seguida ao JBP (com 24,1\%) e à Revista da Associação Brasileira de Psiquiatria (com 6,2\%), ficando as principais revistas de saúde pública e coletiva em segunda ordem numericamente (a que traz maior número de artigos, a Revista de Saúde Pública da USP, apresenta índice de 4,1\%). Além da psiquiatria, outras áreas, que preparam profissionais para atuação na saúde, como psicologia e terapia ocupacional, têm-se dedicado mais ao debate sobre as transformações na saúde mental, do que áreas da saúde pública ou coletiva. Essas, só mais recentemente vêm incorporando o debate. Por exemplo, é significativo que os Cadernos de Saúde Pública, da FIOCRUZ, um dos periódicos de saúde pública mais representativos do país, só traga cinco trabalhos ( $2,1 \%$ da amostra) nas rubricas investigadas. Embora a Reforma na psiquiatria tenha nascido no mesmo campo de lutas da Reforma Sanitária é inegável que guarda com esse movimento diferenciações que lhe dão uma identidade própria e uma feição original na forma como vem experimentando novas práticas e novas relações entre usuários e profissionais da área.

Analisando os trabalhos acadêmicos (dissertações e teses), encontramos uma predominância de disciplinas que, no atual processo, têm dividido espaços com a psiquiatria. Do total de 39 trabalhos, 16 são de duas faculdades de enfermagem; 09 de quatro faculdades de medicina; 08 de três escolas de saúde pública e um programa de medicina social; 04 de um único instituto de psicologia e 01 de um departamento de sociologia política. Uma pesquisa específica de teses acadêmicas seria, neste ponto, esclarecedora. Corroborando os números acima, a observação empírica tem mostrado que enfermagem, psicologia, terapia ocupacional e serviço social são áreas que vêm expandido intensamente sua atuação no campo psiquiátrico, não só numericamente, como em termos de redefinição de suas funções nos serviços.

É significativo o fato de aparecerem dois artigos recentes sobre 'avaliação da qualidade de serviços de saúde mental', na única revista sem relação direta com nossa temática - $R e$ vista de Administração Pública. Muito provavelmente, isto se deve a ser um tipo de investigação vocacionado a produzir efeitos de aplicabilidade concreta e imediata em gestão de serviços, principalmente, de serviços públicos.

Analisando a relação entre conteúdo e fontes das publicações, encontramos uma predominância proporcional de trabalhos com base empírica e voltados para problemáticas psiquiátricas específicas no Jornal Brasileiro de Psiquiatria e na Revista da ABP-APAL. Os textos de conteúdo crítico, mais claramente identificados com a reforma, sejam teóricos ou empíricos, aparecem com mais frequiência em livros, teses, publicações de órgãos oficiais e nos seguintes periódicos da fonte: Saúde em Debate; Revista de Terapia Ocupacional; Psicologia: Teoria e Pesquisa; Saúde Brasileira e Revista de Neurobiologia.

Quanto à região de origem dos trabalhos, encontramos o seguinte quadro. A imensa maioria das referências identificadas são trabalhos de autores da região Sudeste ou sobre experiências desenvolvidas naquela área $(43,7 \%)$. Vem, em seguida, o Nordeste (6\%), o Sul $(5,1 \%)$, e o Norte e o Centro-Oeste (com $1 \%$ cada). O índice de publicações oficiais nacionais somadas às estrangeiras ficou em torno de $11,5 \%$. Em aproximadamente 29\% da amostra, não se pôde detectar, com precisão, a origem. Fica evidenciada, portanto, a forte concentração da produção científica do país na região de maior desenvolvimento socioeconômico, que é, também, uma região de grande concentração de manicômios e dispositivos psiquiátricos (Alves, 1992). É provável que o maior número de experiências de modificação de serviços de saúde mental esteja igualmente concentrado na região Sudeste, em razão do maior número de administrações municipais ligadas a partidos de esquerda; essas administrações têm sido as principais protagonistas da Reforma em nível administrativo público. 


\section{Temáticas dominantes}

Para fornecer um panorama geral do conteúdo dos trabalhos, classificamos a amostra nas seguintes categorias temáticas, em ordem decrescente de números de trabalhos reunidos:

1. Textos sobre organização de serviços - Nesta categoria, foram considerados todos os textos relacionados à proposição, implementação e avaliação de programas e serviços de saúde mental, institucional e comunitária, incluindo os textos de valor oficial, isto é, publicados por órgãos oficiais de saúde. Esta categoria foi dividida em outras seis subcategorias:

a) Relatos/análises de experiências e estudos empíricos exploratórios

b) Avaliações sistemáticas de serviços e da assistência

c) Projetos e propostas

d) Programas e planos oficiais

e) Relatórios oficiais de avaliação - Estes relatórios são, em geral, conclusões de seminários de avaliação, internos a instituições públicas (tais como, por exemplo, o Centro Psiquiátrico Pedro II e a Colônia Juliano Moreira), não correspondendo a pesquisas sistemáticas.

f) Avaliações da reabilitação e reinserção de clientela na comunidade - Esta subcategoria foi diferenciada da anterior porque nem sempre pesquisas sobre clientela estavam relacionadas a uma avaliação do serviço de onde egressava o paciente.

2. Análises teóricas da reforma - Trabalhos de discussão teórica sobre a reforma (atuais políticas, mudanças na assistência, questão de direitos, novos modelos), bem como análises históricas da instituição psiquiátrica, em geral e no Brasil.

3. Estudos clínicos - Trabalhos cuja temática era eminentemente clínica, isto é, versando sobre diagnóstico, tratamento e cura, técnicas e abordagens teóricas psicológicas e terapêuticas. Nos casos em que a questão clínica tratada era abordada desde o ângulo das implicações em termos de práticas institucionais, o trabalho foi, ou duplamente, ou preferencialmente classificado na categoria 1.Textos sobre Organização de Serviços, como, por exemplo, no caso de 'terapêuticas grupais em serviços'.

4. Estudos epidemiológicos - Estudos epidemiológicos em saúde mental e discussão metodológica de investigação nesta área.

5. Publicações de eventos - Relatórios ou anais de congressos, conferências, seminários e eventos científicos de modo geral.

6. Estudos em saúde mental e trabalho - Considerada hoje como área específica de pesquisa.

7. Estudos sócio-antropológicos - Trabalhos de pesquisa sobre problemáticas de saúde mental, cuja abordagem metodológica está relacionada com a etnografia, antropologia, sociologia ou psicologia social.

8. Outros - Textos sem relação direta com a temática deste levantamento, ou excessivamente genéricos (relativos à saúde em geral), ou demasiadamente específicos (tratando de psicologia, psicanálise, etc.).

A tabela 3 apresenta a distribuição quantitativa dos trabalhos.

Esses índices são aproximativos uma vez que se trata de classificação com base em critérios analíticos da investigadora. Em várias ocasiões, o texto caberia em mais de uma categoria. Procurou-se, nesses casos, identificar a ênfase temática, evitando uma dupla classificação. Isso ocorreu em pouquíssimos casos, sendo esse dado considerado no cálculo de percentagens.

Os dados da tabela 3 revelam uma maior predominância de trabalhos sobre organização de serviços de saúde mental (129 trabalhos, ou 34,6\% da amostra), seguida de análises teóricas sobre a reforma ( 86 trabalhos, ou $23,1 \%$ ). No primeiro caso, com predomínio inequívoco de relatos e análises de experiências (35,5\% dos trabalhos da categoria 1), seguidos de avaliações mais sistemáticas de serviços $(23,7 \%)$, com muito poucas avaliações sobre reinserção social do doente mental ( $6,8 \%$ da categoria).

Os números indicam a representatividade da amostra para o presente estudo. Somando-se apenas as duas primeiras categorias, claramente pertinentes ao processo de reforma, teremos $57,7 \%$ da amostra (215 trabalhos), com apenas 2,8\% (11 trabalhos) não apresentando relação direta com o objeto de investigação.

Tabela 3. Distribuição dos trabalhos por temática

\begin{tabular}{llc}
\hline \multicolumn{1}{c}{ Temáticas } & N & Percentagem na Amostra \\
\hline 1. Textos sobre Organização de Serviços & 129 & $34,6 \%$ \\
Relatos/análises de experiências & 45 & $35,5 \%$ desta categoria \\
Avaliações sistemáticas de serviços & 31 & $23,7 \%$ desta categoria \\
Projetos e propostas & 18 & $14,0 \%$ desta categoria \\
Programas oficiais & 14 & $11,0 \%$ desta categoria \\
Relatórios oficiais de avaliação & 12 & $8,9 \%$ desta categoria \\
Avaliações da reinserção & 09 & $6,8 \%$ desta categoria \\
2. Análises Teóricas da Reforma & 86 & $23,1 \%$ \\
3. Estudos Clínicos & 53 & $14,1 \%$ \\
4. Estudos Epidemiológicos & 42 & $11,3 \%$ \\
5. Publicações de Eventos & 18 & $4,9 \%$ \\
6. Estudos em Saúde Mental e Trabalho & 17 & $4,6 \%$ \\
7. Estudos Sócio-antropológicos & 17 & $4,6 \%$ \\
8. Outros & 11 & $2,8 \%$ \\
\hline Total & 373 & $100 \%$ \\
\hline
\end{tabular}


É eloqüente o alto índice de trabalhos sobre organização de serviços, quando são estes últimos, precisamente, o eixo do processo de transformação em curso. Por outro lado, confirmando a percepção empírica, ainda são poucos os trabalhos que tratam da dimensão propriamente social da desinstitucionalização, isto é, do retorno do 'doente mental' ao convívio social. $\mathrm{O}$ índice de trabalhos a respeito dessa questão é um pouco melhorado quando analisamos a categoria Estudos sócio-antropológicos (17 trabalhos, ou 4,6\% da amostra), na qual se inscrevem trabalhos sobre: representação da doença mental por familiares e população; percepção e crenças de trabalhadores da área; atitudes de universitários frente ao doente mental; percepções e representações do próprio paciente.

Os trabalhos classificados na categoria Estudos clínicos tratam de diversas problemáticas: psicológicas, psicossociais, psicanalíticas. Em geral, são discutidas do ponto de vista de como podem comprometer a saúde mental ou estarem relacionadas a "distúrbios mentais", e mesmo a "desvios de comportamento". Estas problemáticas são: adolescência, interações familiares, desnutrição, aleitamento materno, alcoolismo, ciclo menstrual, terceira idade, estresse, dimensões psicológicas de fenômenos sociais, como migração, prostituição, envelhecimento da população, problemas escolares e de aprendizagem, deficiência mental, saúde mental de estudantes de medicina. E ainda, questões relacionadas a diagnósticos, procedimentos e abordagens terapêuticas, uso de psicofármacos, clínica da psicose. Neste último caso, aparecem pouquíssimos textos, talvez porque trabalhos de discussão propriamente técnica sobre clínica da psicose estejam indexados em outros descritores, tais como psiquiatria e psicanálise. Seria o caso de se perguntar se tal dado não estaria corroborando a segunda "divisão de trabalho" do campo, detectada por Jane Russo (1996), a saber, entre os que se ocupam das questões políticas e os que se ocupam da questão técnica propriamente dita, isto é, do manejo da clínica da psicose.

Os trabalhos clínicos, recortando problemáticas psíquicas em sua relação com o binômio saúde/doença mental diminuem sensivelmente na década de 90 , dando lugar a um maior número de trabalhos sobre mudanças nos dispositivos institucionais, ou mesmo, enfocando os tais problemas a partir de perspectivas mais complexas. Isto parece apontar certa mudança de enfoque, de uma perspectiva psicologizante para abordagens que não isolam "problemas psicológicos", mas, buscam, isto sim, analisar esses "problemas" em relação com as próprias práticas institucionais e sociais. No entanto, esta não é uma mudança generalizável. Diríamos apenas que aparece como uma tendência mais recente, nem sempre totalmente explicitada nos próprios trabalhos, mas coerente com o horizonte ético-teórico da desinstitucionalização.

Na maioria dos trabalhos sobre terapêuticas em serviços, classificados na categoria Textos sobre organização de serviços, destacam-se os seguintes aspectos: discussão ou proposição de novos dispositivos (como por exemplo, hospital-dia, interconsultas, Centro de Atenção Psicosocial e Núcleo de Atenção Psicosocial); papel e inserção de diferentes profissionais em equipes multiprofissionais (principalmente, enfermeiro, psicólogo e terapeuta ocupacional); atividades desenvolvidas dentro dos dispositivos, em geral, atividades grupais (terapêuticas, de lazer e arte) com pacientes crônicos de manicômios, semi-internos de hospitais-dia, e de centros de convivência. Atividades com familiares e população aparecem em número bem menor. A ênfase é colocada nas vantagens ético-morais dessas novas atividades com o paciente, tanto em relação aos procedimentos de mera internação e medicação, quanto na comprovada diminuição de reinternações dos pacientes destes serviços. Nos trabalhos classificados nesta primeira categoria, predominam os relatos de experiências de modificação de serviços, sobressaindo a discussão das dificuldades em implementar as mudanças em dispositivos já existentes, bem como, a necessidade de adequação, preparo e formação de profissionais para atuação em equipes dentro das novas propostas. Nesse sentido, chama particularmente a atenção o grande número de textos sobre atuação da enfermagem, em saúde mental, em trabalhos que focalizam recorrentemente uma discussão identitária sobre o papel do enfermeiro, auxiliares e atendentes, entre si e nas equipes multiprofissionais, e, sobretudo, na relação com os pacientes, aparecendo alguns poucos textos que problematizam a prática institucional.

Na década de 90, aumentam as análises e relatos de experiências e as avaliações de serviços, ao passo que os projetos e propostas se concentram na década de 80 e diminuem na seguinte. Aparece uma primeira pesquisa de avaliação de serviço em 1982, mas esse campo de investigação só se desenvolverá a partir dos anos de 1984 e 1985, com acentuado aumento na década de 90 . Tal fato é coerente com um processo de mais de vinte anos. É natural que o desafio hoje seja a avaliação das experiências institucionais já desenvolvidas (Vasconcelos, 1995). Nesse período, destacam-se os artigos de Pitta (1996), Pitta e cols. (1995) e Filho e cols. (1996), que trazem relatos parciais de pesquisas multicêntricas de avaliação.

As pesquisas de avaliação de serviços e assistência avaliam aspectos tais como: índice de reinternações; cobertura dos serviços à população; abandono de tratamento; sistemas de notificação de egressos; características de ações e programas; comparação entre diferentes tipos de funcionamento de serviços; atuação de equipes; satisfação dos usuários; adequação ou não de instrumentos diagnósticos à clientela; motivos de internação. Existem também muitas pesquisas epidemiológicas com aplicações em avaliação de serviços, tais como: perfis de demanda e de clientela psiquiátrica; prevalência e níveis de transtornos mentais em população de abrangência dos serviços; determinantes ambientais de adoecimento mental, entre outras.

Na categoria Estudos em saúde mental e trabalho, aparecem, basicamente, problemáticas relacionadas a fatores de risco de transtornos mentais ou sofrimento psíquico em determinados tipos de atividades profissionais. Dentre elas, poderíamos citar: limpeza urbana; trabalho em sistema de turnos; trabalho em hospitais gerais e psiquiátricos; trabalhos repetitivos ou com ausência de produto (bancários, por exemplo). Há predominância de pesquisas empíricas quantitativas, vindo em seguida discussões sobre fundamentação teórica.

$\mathrm{Na}$ categoria Estudos sócio-antropológicos estamos incluindo todos os trabalhos que, pela temática e/ou estratégia metodológica, aproximam-se de um enfoque sociológico, antropológico, etnográfico ou da psicologia social. Os temas desses trabalhos são: construção social da doença mental; 
análises de representações; significações sociais e discursos a propósito de drogas; doença mental e práticas de cura; análise teórica sobre a categorização normal e anormal; e estudos sociohistóricos de instituições totais concretas, como, por exemplo, o manicômio do Juqueri, em São Paulo. O índice de publicações nesta categoria $(4,6 \%)$ demonstra que ainda são relativamente poucos, os trabalhos que seguem uma metodologia mais sistemática de investigação em ciências sociais. Predominam, no campo, análises e relatos livres de experiências, bem como estudos exploratórios. Os estudos teóricos ( Análises teóricas da reforma) é que avançam na direção de análises histórico-políticas mais sistemáticas, constituindo grande parcela da amostra $(23,1 \%)$.

Consulta aos Cadernos do IMS (Instituto de Medicina Social da UERJ), mostrou, nesse aspecto, tendência contrária à amostra. Chama a atenção, o grande número proporcional de pesquisas sócio-antropológicas em questões de saúde mental, sendo muitos dos autores vinculados ao programa de pósgraduação do Museu Nacional de Antropologia da UFRJ. São trabalhos que claramente problematizam a linguagem e as representações psicologizantes de estratégias terapêuticas, discutindo representações de saúde/doença e doença mental. Este acento em análises sócio-antropológicas parece ser uma forte característica do programa de pós-graduação em medicina coletiva do Instituto, principalmente vinculadas à área de concentração "Ciências Humanas e Saúde".

Procuramos identificar se havia uma progressão no número de publicações da amostra. Observamos um aumento progressivo na quantidade de textos na direção dos últimos anos. A título ilustrativo, considerando uma periodização arbitrária de cinco em cinco anos, temos o seguinte quadro (ver tabela 4).

Tabela 4. Número de trabalhos por períodos de cinco anos

\begin{tabular}{lc}
\hline Período & Número de Textos \\
\hline 1980 a 1984 & 66 \\
1985 a 1989 & 108 \\
1990 a 1994 & 169 \\
\hline
\end{tabular}

Alguns anos se destacam por um acentuado aumento no número de publicações, o que nos levou a pesquisar uma possível relação entre aumento de produtividade e acontecimentos marcantes no movimento. Comprovamos o seguinte. Os anos que se destacam são: 1983 - 26 textos, para uma média de 10, nos outros quatro anos do período; 1987 - 29 textos, para uma média de 20 , nos outros quatro anos do período; 1992 - 49 textos e 1993 - 40 textos, nestes dois últimos casos, para uma média de 28 textos, nos outros quatro anos do período.

Se compararmos os anos acima destacados, como de maior concentração da produção científica, com aqueles em que ocorreram eventos importantes no movimento, verificaremos que tendem à convergência. Assim, em agosto de 1982, é criado o plano para a assistência psiquiátrica do CONASP (Conselho Consultivo da Administração de Saúde Previdenciária, ligado ao Ministério da Previdência e Assistência Social), que ficou conhecido como "plano do Conasp". Segundo Amarante (1995), este plano "inspirado nas propostas do Cebes [Centro Brasileiro de Estudos em Saúde] de criação de um Sistema Único de Saúde (p. 75)" foi o primeiro mecanismo oficial de impacto sobre a assistência psiquiátrica manicomial e privatista, colocando ênfase no ambulatório como elemento central de atendimento. É considerado como um fato importante que fez acelerar a reforma.

Em dezembro de 1987 ocorre, em Bauru/SP, o II Congresso Nacional de Trabalhadores em Saúde Mental. Este evento, precedido pela I ${ }^{a}$ Conferência Nacional de Saúde Mental, realizada em junho de 1987, acontece num clima acalorado de debates e propõe a radicalização do movimento, adotando o lema "Por uma Sociedade sem Manicômios". O II Congresso dos Trabalhadores em Saúde Mental do Estado de São Paulo, organizado pouco antes, em outubro de 1986, teve, segundo Amarante, um papel decisivo para o movimento dos TSM criticado, então, como sendo "comandado por lideranças ultrapassadas e... muito comprometidas com o poder público" (Amarante, 1995, p.86). Tal radicalização teria sido reforçada por repercussões do terceiro encontro da Rede Latino-Americana de Alternativas à Psiquiatria, ocorrido em Buenos Aires em dezembro de 1986, que contou com participações importantes do movimento internacional como Félix Guattari, Franco Rotelli e Robert Castel.

Em relação aos anos de 1992 e 1993, é possível associar ao primeiro, a realização da II ${ }^{a}$ Conferência Nacional de Saúde Mental, ocorrida em dezembro. É natural que evento tão importante tenha repercutido na produção de muitos textos, tanto preparatórios quanto subseqüentes. A relação entre o aumento de publicações em anos marcados por importantes eventos do movimento, pode ser indicativo da importância da realização de fóruns de debate como incentivo à investigação e publicação.

\section{Abordagens metodológicas identificadas: a problemática dicotomia entre "qualitativo" $\mathrm{e}$ "quantitativo"}

Ao decidirmos pelo alargamento dos propósitos deste trabalho para um mapeamento mais geral que incluísse a produção científica de natureza qualitativa e quantitativa, pensávamos que essas últimas seriam majoritárias no universo investigado. Entretanto, analisando as abordagens metodológicas da amostra, deparamo-nos com uma outra realidade. Ao contrário do esperado, nos 373 trabalhos da amostra, encontramos 62 onde predominava o enfoque quantitativo contra 83 que claramente privilegiavam o enfoque qualitativo.

Para se chegar a este resultado, foram considerados apenas os trabalhos em cujos resumos se encontrasse explicitado o método adotado, ou onde constassem elementos descritivos dos procedimentos e objetivos do trabalho, suficientes para se concluir por uma ou outra classificação da abordagem, com baixa possibilidade de equívocos. Em 11 trabalhos foi impossível identificar a abordagem metodológica adotada, e em outros seis preferimos considerar como pesquisas mistas, pois ambos os enfoques eram adotados, sem privilégio evidente de nenhum deles. Nesta classificação, foi considerado o fator predominância e não exclusividade do uso de métodos e técnicas quantitativos ou de tipo interpretativo. Uma diferenciação rígida entre estes termos nos parece improcedente em se tratando de análise de realidades complexas. 
Sem nos alongarmos na discussão dessa polêmica questão metodológica, sobre a qual já existem muitos estudos pertinentes (Minayo, 1992), é importante esclarecer que tal distinção qualitativo/quantitativo pode ser útil apenas na medida em que revela a predileção do investigador por diferentes critérios de legitimidade ou confiabilidade dos resultados e conclusões de sua investigação. Assim é que, segundo uma tradição mais positivista de ciência, a quantificação ou experimentação com métodos de controle por parte do investigador é vista, em geral, como imprescindível. Ao contrário, numa perspectiva inserida na tradição hermenêutica (Minayo, 1992), seria fundamental a explicitação dos objetivos e do tipo de aproximação ou olhar interpretativo com que se estaria construindo a investigação da realidade. Acredita-se, neste caso, que toda investigação de realidades complexas é sempre uma construção ou interpretação possível e elucidativa, mas nunca necessária ou exata.

Esta pesquisa nos fez rever a idéia de uma distinção rígida entre qualitativo e quantitativo como pouco sustentável do ponto de vista científico. Preferimos pensar que é igualmente válido fundamentar a interpretação tanto em observação participante, em estudos de caso, em análises de discursos, em narrativas e histórias de vida, quanto em instrumentos padronizados, em quantificações estatísticas, em controle experimental. O objetivo ou objeto da investigação, sendo o fiel da balança, é o que decidirá a pertinência dos métodos empregados.

Em relação aos nossos resultados, na categoria qualitativa foram incluídas análises acadêmicas sistemáticas e avaliações da qualidade de serviços desde que tivessem claramente privilegiado métodos interpretativos de investigação. Na categoria quantitativa estão todos os estudos empíricos que privilegiaram dados obtidos por meio de instrumentos estatísticos e/ou de controle. Dois motivos podem estar na base da predominância da abordagem qualitativa. O primeiro, de ordem hermenêutica, é que as problemáticas que definem o suposto "campo da saúde-doença mental" sempre remetem a uma discussão teórica, ética, política ou estética. Isto é, são passíveis de uma problematização reflexiva e não apenas de constatações empíricas. Por se tratar de problemas humanos, inseridos em relações sociais e institucionais, estarão sempre relacionados a 'modos de vida' condicionados social e historicamente. São, portanto, passíveis de infinitas novas reinterpretações, na medida em que são problemáticas que nos remetem, seja prática, seja teoricamente, para uma multiplicidade de estratégias, técnicas e métodos de enfrentamento (terapêuticos, político-jurídicos, institucionais). São as vivências e experiências nas relações sociais que configuram os discursos e as práticas no chamado campo da saúde mental. Da mesma forma, toda análise investigativa passa a ser, necessariamente, mais um discurso a povoar o campo.

O outro motivo da predominância da abordagem qualitativa é mais prosaico. Deve-se ao fato deste levantamento não incluir rubricas onde poderiam estar concentrados trabalhos predominantemente quantitativos, como por exemplo, "psiquiatria" e "epidemiologia psiquiátrica". Esta última, no entanto, não foi encontrada, nem mesmo dentro da rubrica "epidemiologia", que contém mais de 15 descritores diferentes.
As pesquisas quantitativas, principalmente aquelas relacionadas à avaliação de serviços e a perfis de clientela (sóciodemográficos e epidemiológicos), concentram-se na década de 90, ou melhor dizendo, mais que duplicam em relação aos anos 80. Este dado pode estar indicando uma necessidade de se precisar em "dados quantitativos" as discussões e opções teóricas e práticas. Mas podem, também, estar indicando uma nova tendência à dominância de abordagens mais positivistas, dimensão que precisaria ser melhor investigada. Pesquisas desse tipo são publicadas, em sua maioria, em revistas especializadas de psiquiatria e medicina.

\section{Teses e livros}

Consideração à parte deve ser feita às teses e livros. As teses, que justificam estudos específicos, tais como o feito por Leone (2000), encontravam-se precariamente indexadas no banco de dados consultado na época do presente levantamento. No caso de livros, que não constitui a especialidade do banco pesquisado, a amostra não é tão representativa porque já possuímos uma produção bem maior, identificada com o ideário da desinstitucionalização. É significativa a quantidade de publicações em livros nos últimos anos, principalmente se levarmos em conta que o livro é um espaço privilegiado para divulgação de trabalhos mais autônomos e para um questionamento mais radical da instituição psiquiátrica. Tal espaço tem sido efetivamente usado para divulgação de experiências mais ousadas, que têm se multiplicado pelo país.

Nesse sentido, também a divulgação da produção de programas de pesquisa avançada, como, por exemplo, os mencionados Cadernos do IPUB, da Pós-Graduação do Instituto de Psiquiatria da UFRJ, e os Cadernos do IMS e a Revista Physis, ambos da UERJ, têm cumprido papel importante.

\section{Considerações Finais}

O objetivo deste projeto foi esboçar uma cartografia da produção científica brasileira no campo da saúde mental, a partir de amostra abarcando o período que vai de 1980 a 1996. Procurou-se identificar as principais tendências e aspectos de evolução dessa produção, analisando-se sua relação com o atual processo de Reforma Psiquiátrica. O propósito final foi demonstrar o impacto do movimento sobre a referida produção científica. O período coberto pela amostra corresponde ao início e primeiros anos de consolidação da Reforma. A amostra selecionada demonstrou ser pertinente aos propósitos do estudo, tanto pelo conteúdo das publicações, quanto pelo fato de contemplar os principais periódicos nacionais das áreas da saúde e da saúde mental.

Das 373 referências analisadas, 241 eram artigos, distribuídos em 49 revistas especializadas; 39 trabalhos acadêmicos (dissertações e teses); 39 publicações de órgãos oficiais, definidores de políticas; 37 livros e 17 publicações de eventos do movimento ou de entidades de classe. Encontrou-se uma enorme concentração da publicação na região Sudeste, com $43,7 \%$ da amostra, enquanto que para todas as outras regiões as porcentagens ficaram bem abaixo de dois dígitos; ressalve-se o fato de que em $29 \%$ não foi possível identificar a origem regional. As temáticas, muito diversificadas, foram agrupadas em oito categorias de análise com predomínio de 
duas, diretamente relacionadas à reforma: Organização de serviços (34,6\% da amostra) e Análises teóricas da reforma $(23,1 \%)$, que totalizaram mais da metade da amostra. Trabalhos relativos a projetos e propostas são predominantes na década de oitenta e diminuem na década seguinte, quando, então, aumentam os textos de análises, relatos de experiências e avaliações de serviços, numa clara sintonia com a evolução do processo.

Como principais tendências identificadas neste estudo, podemos dizer que em termos de periódicos, aparecem poucas publicações ligadas à temática da reforma psiquiátrica em revistas de saúde em geral e de saúde pública ou coletiva. Dentre os periódicos especializados e mais afins à temática, o $J B P$ é francamente o que mais se destaca em número de publicações pertinentes. Significativo é que apenas um periódico local, com menos de seis artigos indexados no banco de dados consultado, traga no título referência explícita à área da saúde mental: o Arquivo da Coordenação de Saúde Mental do Estado de São Paulo. Conclui-se que não há uma revista de âmbito nacional destinada exclusiva ou prioritariamente à reforma, já que a série SaúdeLoucura, da Hucitec, não possui características de periódico.

Com relação às temáticas tratadas nas publicações, o maior número de trabalhos gira em torno de questões sobre organização de serviços, com aumento significativo e progressivo, no sentido dos últimos anos do período considerado, de avaliações de serviços, que começam a aparecer na metade dos anos oitenta. É baixo o número de estudos sócio-antropológicos no período. Foi identificada certa tendência recente para uma mudança de enfoque nos trabalhos clínicos: de uma perspectiva psicologizante para abordagens que não isolam problemas psicológicos de sua complexidade social e institucional. Em termos de evolução, a cada novo período de cinco anos, duplica o número anterior de publicações. Os anos em que ocorrem, ou que sucedem eventos importantes do movimento, apresentam significativo aumento no número de publicações, demonstrando o impacto de acontecimentos políticos sobre a produtividade científica.

Quanto à metodologia, há predominância de abordagens qualitativas e mistas sobre abordagens essencialmente quantitativas. No entanto, estas últimas mais que duplicam na segunda década estudada em relação à primeira. Este fato pode estar relacionado a uma nova tendência metodológica ou a uma real necessidade de se somar às discussões iniciais, de tipo mais descritivo e reflexivo, dados quantificados.

Em termos de maior ou menor alinhamento com o ideário antimanicomial do movimento, a amostra é bem heterogênea. Encontramos textos de conteúdo progressista-reformista, de perspectivas psicológicas e médicas conservadoras, de crítica moderada ao modelo tradicional (preferindo falar de ineficiências do sistema), até aqueles afinados com as propostas mais radicais das reformas sanitária e psiquiátrica. No entanto, encontramos apenas um texto francamente crítico ao movimento da reforma, fazendo defesa aberta do "bom" hospital, que só seria ruim quando ineficiente ou desumano.

A partir de 1983, os trabalhos referem-se a mudanças que enfocam o tratamento ambulatorial como preferencial, em oposição à internação, e ressaltam a importância da atenção primária ou básica à saúde e a necessidade de se trabalhar em equipes multiprofissionais. Na década de oitenta, os trabalhos ainda são um pouco tímidos na avaliação da assistência e apresentam abordagens mais prescritivas. Aos poucos, vão aparecendo trabalhos mais avaliativos e críticos aos dispositivos assistenciais tradicionais apontando o grande desafio que significa transformá-los em sua essência.

\section{Referências}

Alves, D. S. (1992).Transformações na assistência psiquiátrica no Brasil. Em J. Russo \& J. F. Silva Filho (Orgs.), Duzentos anos de psiquiatria (pp.135-143). Rio de Janeiro: Relume Dumará/UFRJ.

Amarante, P.D. (Org.). (1995). Loucos pela vida. Rio de Janeiro: Panorama/ENSP.

Amarante, P.D.(1996). O homem e a serpente: outras histórias para a loucura e a psiquiatria. Rio de Janeiro: Fiocruz.

Birman, J. (1992). A cidadania tresloucada. Em B. Bezerra \& P. Amarante (Orgs.), Psiquiatria sem hospício: contribuições ao estudo da reforma psiquiátrica (pp. 71-90). Rio de Janeiro: Relume-Dumará.

Birman, J. \& Costa, J.F. (1994). Organização de instituições para uma psiquiatria comunitária. Em P. Amarante (Org.), Psiquiatria social e reforma psiquiátrica (pp. 41-72). Rio de Janeiro: Fiocruz.

Filho, J.F. da S., Cavalcanti, M.T., Cadilhe, G.R., Vilaça, A.T., Avancini, E., Machado, H.O., Perecmanis, L., Maisonnette, M.J., Rocha E.C., Carreteiro, R.O., Mozinho, G..M.P. \& Pitta, A.M. (1996). Avaliação de qualidade de serviços de saúde mental no Município de Niterói - R.J. A satisfação dos usuários como critério avaliador. Jornal Brasileiro de Psiquiatria, 45(7) 393-402.

Leone, E.B. (2000). Balanço da produção acadêmica brasileira no campo da saúde mental - 1990/97. Revista de Ciências Humanas. edição especial: saúde mental: uma perspectiva crítica, 121-151.

Minayo, M.C. (1992). O desafio do conhecimento: pesquisa qualitativa em saúde. São Paulo-Rio de Janeiro: Hucitec-Abrasco.

Nicácio, F. (Org.) (1990). Desinstitucionalização. São Paulo: Hucitec.

Pitta, A.M.F. (1996). Cuidados com o cuidar: estratégias de avaliação. Cadernos IPUB. Por uma assistência em transformação, 3, 159-170.

Pitta, A.M.F., Filho, J.F. da S., Souza, G.W., Lancman, S., Kinoshita, R.T., Cavalcanti, M.T. \& Valentini, W.H. (1995). Determinantes da qualidade de serviços de saúde mental em municípios brasileiros. Estudo da satisfação com os resultados das atividades desenvolvidas por pacientes, familiares e trabalhadores dos serviços. Jornal Brasileiro de Psiquiatria, 44 (9), 441-452.

Russo, J. (1996). O que está em jogo numa reforma psiquiátrica. Cadernos IPUB. As políticas públicas no Município de Angra dos Reis, 4, 96-99.

Vasconcelos, E. (1995). Avaliação de serviços no contexto da desinstitucionalização psiquiátrica: revisão de metodologias e estratégias de pesquisa. Jornal Brasileiro de Psiquiatria, 44(4),189-197.

Recebido em 11.07.2002

Primeira decisão editorial em 27.06.2003

Versão final em 11.08.2003

Aceito em 24.10.2003 


\title{
INTERESSADO EM AGILIZAR A TRAMITAÇÃO DE SEU MANUSCRITO?
}

\author{
Informações e dicas para os autores \\ sobre aspectos de forma
}

\section{O manuscrito é encaminhado para exame}

O manuscrito é revisto por consultores ad hoc, pelo Conselho Editorial e na secretaria da revista. $\mathrm{O}$ exame pode ser mais rápido se o manuscrito está bem escrito e se já foi bem revisto pelo autor (incluindo revisão ortográfica e de consistência na apresentação de referências).

Textos mal redigidos comprometem o exame de mérito do conteúdo. Manuscritos mal preparados ou mal redigidos são sumariamente rejeitados. Manuscritos que parecem potencialmente interessantes para publicação mas que devem passar por modificações substanciais podem ser candidatos a uma tramitação prolongada. Manuscritos com inconsistências na apresentação de referências têm a tramitação prolongada com a consulta aos autores para as devidas correções.

\section{Trecho selecionado do Manual da APA (4 edição)}

Conforme apropriadamente lembrado no Manual da American Psychological Association [APA] (1994), referências preparadas com acuidade são pontos a favor da credibilidade do autor como um pesquisador cuidadoso. De outro lado, conforme citado no Manual de APA (p. 175): "Uma referência incompleta e não acurada "ficará impressa como um incômodo para futuros investigadores e um monumento ao descuido do escritor' (Bruner, 1942, p. 68)".

American Psychological Association. (1994). Publication manual of the American Psychological Association ( $4^{\text {a }}$ ed.). Washington, DC: Autor.

\section{Informações e dicas para os autores sobre aspectos de conteúdo}

Na reformulação de seu manuscrito o autor deve procurar atender às indicações dos pareceristas que atuam como leitores críticos de seu trabalho. Quando o autor discorda das indicações, cabe argumentação - menos no sentido de afirmação categórica de razões pessoais de preferência e mais de apresentação de argumentos que justifiquem o mérito científico de sua posição. 